\section{Responses to Biological Therapy in Severe Eosinophilic Asthma}

Alvarez-Puebla $\mathrm{MJ}^{1,2,3,4}$, Arroabarren $\mathrm{E}^{2}$, Zavala $\mathrm{MJ}^{2}$, Corcuera $\mathrm{A}^{2,3}$, Olaguibel A ${ }^{3}$, Olaguibel JM ${ }^{1,2,3,4}$

${ }^{1}$ Unidad de Asma Grave, Complejo Hospitalario de Navarra, Pamplona, Spain

${ }^{2}$ Servicio de Alergología, Complejo Hospitalario de Navarra, Pamplona, Spain

${ }^{3}$ NavarraBioMed, Gobierno de Navarra, Pamplona, Spain

${ }^{4}$ CIBER Respiratorio

J Investig Allergol Clin Immunol 2019; Vol. 29(4): 335-337 doi: $10.18176 /$ jiaci.0403

Key words: Biologics. Eosinophilia. Severe asthma. Response to therapy.

Palabras clave: Biológicos. Eosinofilia. Asma grave. Respuesta al tratamiento.

\section{To the Editor:}

Severe asthma often remains uncontrolled despite high doses of inhaled corticosteroids and a second controller drug $[1,2]$. Biological therapy reduces the frequency of severe asthma exacerbations (SAEs) and improves lung function. Consequently, it is a promising therapeutic option. The biologics currently indicated in severe asthma include the following: omalizumab, which blocks IgE; mepolizumab and reslizumab, which target free serum IL-5; benralizumab, which depletes eosinophils by blocking the IL-5 receptor; and dupilumab, which blocks the IL-4/IL-13 axis. All of these agents are more effective in asthma characterized by type 2 inflammation and eosinophilic asthma. However, even in these phenotypes, individual responses vary and are unpredictable. Therefore, patients should be reevaluated during the first year of treatment and continue with treatment only if the response is adequate [3]. The National Institute for Health and Care Excellence defines an adequate response as a $\geq 50 \%$ reduction in the frequency of SAEs or in the corticosteroid dose needed to maintain control [3].

We report the response to biological therapies in 2 patients with severe asthma [1,2]. Given that the presentation of asthma was similar in both cases similarity of their asthma, we initially assumed that the response to therapy would be comparable.

Patient 1 was 51-year-old woman with a 30 -year history of asthma and rhinosinusitis with nasal polyps. She had had adrenal insufficiency for 3 years and required daily treatment with methylprednisolone $(5 \mathrm{mg})$. She had experienced 3 episodes of eosinophilic pneumonia. Total serum IgE was 78$422 \mathrm{kU} / \mathrm{L}$, and her blood eosinophil count varies from 100 to $300 / \mu \mathrm{L}$. The Asthma Control Test score ranged from 11 to 25.
Patient 2 was a 51-year-old man with a 15 -year history of asthma and rhinosinusitis with nasal polyps. Total serum IgE was $202-330 \mathrm{kU} / \mathrm{L}$, sputum eosinophilia was 5\%-75\%, and the blood eosinophil count was 300-800/ $\mu \mathrm{L}$. The Asthma Control Test score ranged from 8 to 25 .

Neither patient was obese (body mass index, 29 and 28). Tests for dyspnea and anxiety were always negative. Both patients were sensitized to perennial allergens (Patient 1 to Cupressus pollen and animal dander and Patient 2 to Dermatophagoides pteronyssinus), had documented bronchial reversibility, and tolerated nonsteroidal anti-inflammatory drugs. They were taking fluticasone $(1000 \mu \mathrm{g})$, formoterol $(40 \mu \mathrm{g})$, and tiotropium $(5 \mu \mathrm{g})$, and adherence to treatment was good. We calculated the annual average number of SAEs by multiplying the number of SAEs by 12 and dividing the result by the number of months in which they were recorded. The duration of treatment was different for each patient depending on the clinical decisions made (Figure). In both cases, 1 year of therapy with omalizumab failed to reduce the number of SAEs (from 4/y to 6.67/y in Patient 1 and from 6.0/y to 7.2/y in Patient 2).

After completion of therapy with omalizumab, Patient 1 experienced an episode of eosinophilic pneumonia. Since starting mepolizumab (100 mg/4 wk) in October/2017, she has been symptom-free, with no SAEs and a $340-\mathrm{mL}$ increase in mean $\mathrm{FEV}_{1}$ value.

Six months after discontinuation of omalizumab, Patient 2 initiated mepolizumab at $100 \mathrm{mg} / 4 \mathrm{wk}$. After the first 4 months, SAEs reappeared with their usual frequency. Consistent with data reported elsewhere [4], we decided - together with the patient, the Ethics Committee, and the Pharmacy Departmentto increase the dose of mepolizumab to $200 \mathrm{mg} / 2 \mathrm{wk}$. During the following 10 months, the SAE rate dropped to 4.8/y (33\%), although the patient complained of muscle pain that interfered with his activity. In August 2018, we stopped mepolizumab and started intravenous, weight-adjusted reslizumab (30 mg/4 wk). The initially milder muscle symptoms disappeared, and the SAE rate dropped to $2.4(66 \%)$. However, since initiation of anti-IL-5 therapy, his mean $\mathrm{FEV}_{1}$ values dropped by $237 \mathrm{~mL}$ and mean exhaled nitric oxide (ENO) values increased from $70 \mathrm{ppb}$ to $106 \mathrm{ppb}$. Moreover, SAEs became less sensitive to systemic corticosteroids, thus necessitating longer treatment regimens (from 5 to 10 days).

Given that both patients had undergone conventional treatment and had similarly high eosinophil counts and SAE rates, they were candidates for anti-IL-5 therapy. However, their response to mepolizumab differed radically. Mepolizumab was completely successful in Patient 1, who remains symptom-free after 1 year and has improved lung function. Patient 2 experienced an initial 4-month improvement with mepolizumab, although the frequency of SAEs returned to pretherapy values. In premarketing trials, intravenous mepolizumab at $750 \mathrm{mg}$ and $75 \mathrm{mg}$ reduced the 
A

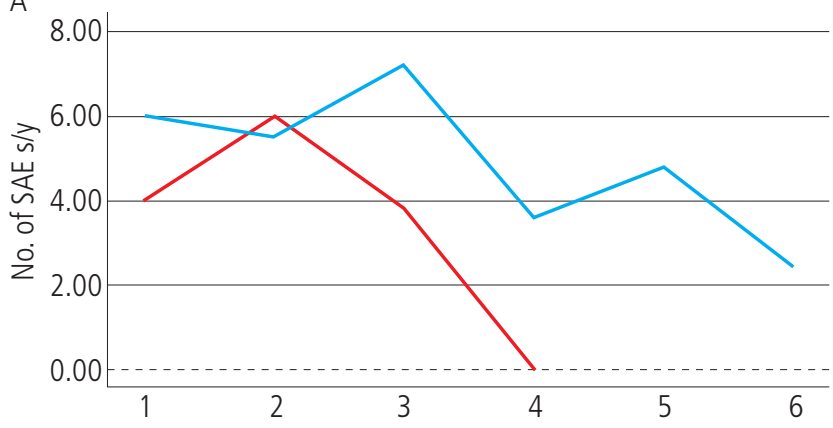

C

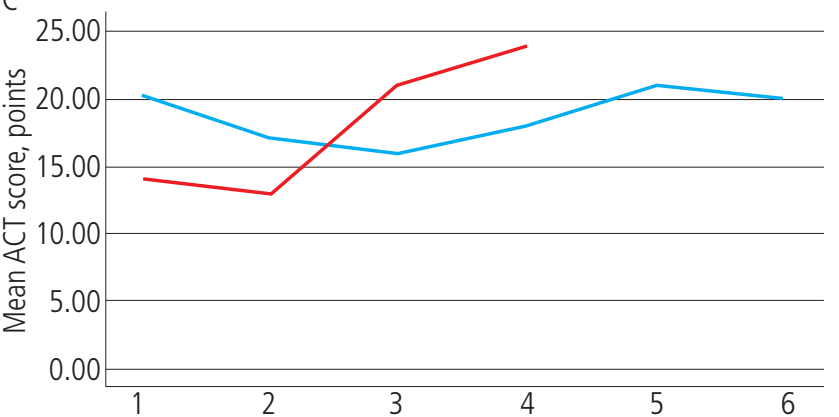

B

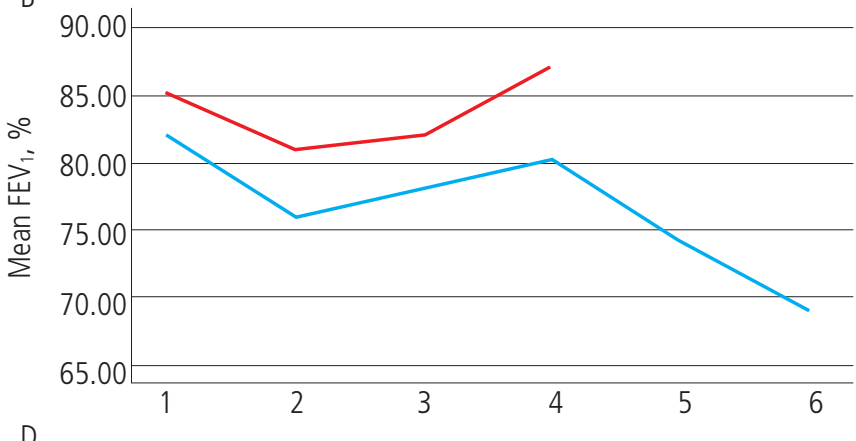

D

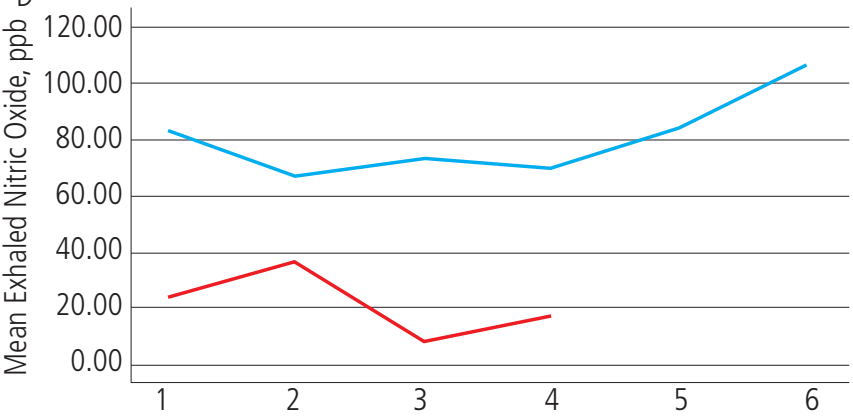

— Patient 1 Patient 2

Figure. Annualized SAE rate (A), mean FEV values (B), mean ACT score (C), and mean ENO values (D) for each time period on the horizontal axis, as follows: 1, Before starting treatment with omalizumab; 2, During treatment with omalizumab; 3, After treatment with omalizumab; 4, During treatment with mepolizumab at $100 \mathrm{mg} / 4 \mathrm{wk} ; 5$, During treatment with mepolizumab at $200 \mathrm{mg} / 2 \mathrm{wk}$ (only for Patient 2); 6, During treatment with reslizumab (only for Patient 2). SAE indicated severe asthma exacerbation; ACT, Asthma Control Test; ENO, exhaled nitric oxide.

SAEs and blood eosinophil counts. Nevertheless, the 75$\mathrm{mg}$ dose was significantly less effective in reducing sputum eosinophil counts [5] and was equivalent to the subcutaneous $100-\mathrm{mg}$ dose that was eventually marketed [6]. It is possible that the administration of antibody at suboptimal doses leads to immune-complex formation that would constitute a local reservoir of IL-5, thus perpetuating bronchial eosinophilic inflammation [7]. Therefore, we increased subcutaneous mepolizumab to $200 \mathrm{mg} / 2 \mathrm{wk}$. The frequency of SAEs dropped by $33 \%$, although the patient experienced disabling muscular symptoms.

Intravenous reslizumab also blocks free IL-5; however, its dose is adjusted for body weight, thus enabling higher doses. Since both dosing and route of administration can modify the clinical response to anti-IL-5 therapy [4,7], we changed highdose mepolizumab for intravenous reslizumab. After 8 months of treatment, the frequency of SAEs fell by $66 \%$. However, we consider this response to be unsatisfactory, as both mean ENO and $\mathrm{FEV}_{1}$ values worsened after initiation of anti-IL-5 therapy and daily bothersome symptoms of asthma reappeared.

It is speculated that respiratory epithelium can be so damaged in some patients with severe asthma that its response to stimuli involves release of epithelial-derived alarmins (thymic stromal lymphopoietin, IL-33, IL-25) that can promote local eosinopoiesis, thus rendering systemic anti-IL-5 therapies ineffective [7]. In the near future, we will try to control asthma in Patient 2 by completely blocking eosinophils with benralizumab.
ENO values were much higher in Patient 2 and may account for the difference in response to anti-IL-5 therapy. However, Patient 1 was taking daily oral corticosteroids, to which ENO is highly sensitive. Since ENO production is associated with type 2 and epithelial cells, dupilumab, which blocks the IL-4/ IL-13 axis, could be an alternative in Patient 2, although we do not know the effect of the initial dupilumab-induced increase in eosinophil count [8]. In theory, we could combine dupilumab and benralizumab.

In contrast with clinical trials, where inclusion criteria are well controlled, real-world practice has not yet yielded sufficient data to generate indicators that predict the response to biological therapy for severe asthma. Blood eosinophils, ENO values, and SAE rate are weak markers that do not take into account the heterogeneity of asthma or the not necessarily parallel change in its different facets (functional, clinical, inflammatory), as was the case in Patient 2, who experienced functional deterioration despite experiencing fewer SAEs. The lack of data enabling us to presume the superiority of any antiasthma biologic means that we need to obtain such information empirically from daily clinical practice. We are therefore indebted to the patients we treat. According to Drazen and Harrington [9], it is essential to have independent comparative studies performed by well-established public institutions in which therapies are supplied cost-free by pharmaceutical companies. Only then can we be sure to prescribe the most appropriate treatment. Finally, the lower sensitivity of Patient 2 to corticosteroids for treatment of SAEs 
should be assessed in the context of eosinopenia induced by anti-IL-5-therapy and should lead us to revisit the role of oral corticosteroids [10].

\section{Funding}

The authors declared that no funding was received for the present study.

\section{Conflicts of Interest}

MJ Zavala reports personal fees from GSK. JM Olaguibel reports personal fees from AstraZeneca and GSK and grants from Sanofi. The remaining authors declare that they have no conflicts of interest.

\section{References}

1. Barranco $P$, Pérez-Francés $C$, Quirce $S$, Gómez-Torrijos $E$, Cárdenas R, Sánchez-García $S$, et al. Consensus document on the diagnosis of severe uncontrolled asthma. J Investig Allergol Clin Immunol. 2012;22(7):460-75.

2. Plaza Moral V, Alonso Mostaza S, Alvarez Rodriguez C, Gomez-Outes S, Gómez Ruiz F, López Vinma A, et al. Spanish Guideline on the management of asthma. J Investig Allergol Clin Immunol. 2016; 26 suppl1:1-92.

3. Bermejo I, Stevenson M, Cooper K, Harman S, Hamilton J, Clowes $M$, et al. Mepolizumab for treating severe eosinophilic asthma: an evidence review group perspective of a NICE single technology appraisal. PharmacoEconomics https:// www.ncbi.nlm.nih.gov/pubmed/?term=Mepolizumab+for+tr eating+severe+eosinophilic+asthma\%3A+an+evidence+rev iew+group +perspective + of $+a+N I C E+$ single+technology $+a$ ppraisal.2018;36(2):131-44.

4. Mukherjee $M$, Aleán Páramo F, Kjarsgaard M, Salter B, Nair G, LaVigne N, et al. Weight-adjusted intravenous Reslizumab in severe asthma with inadequate response to fixed-dose subcutaneous Mepolizumab. Am J Resp Crit Car Med. 2018:197(1):38-46.

5. Pavord ID, Korn S, Howarth P, Bleecker ER, Buhl R, Keene ON, Ortega $\mathrm{H}$, et al. Mepolizumab for severe eosinophilic asthma (DREAM): a multicentre, double-blind, placebo-controlled trial. Lancet. 2012:380:651-9

6. Ortega HG, Liu MC, Pavord ID, Brusselle GG, Fitzgerald JM, Chetta A, et al. Mepolizumab treatment in patients with severe eosinophilic asthma. N Engl J Med. 2014;371(13):1198-207.

7. Bhalla A, Mukherjee M, Nair P. Airway eosinopoietic and autoimmune mechanisms of eosinophilia in severe asthma. Immunol Allergy Clin N. 2018:38:639-54.

8. Sastre J, Davila I. Dupilumab: a new paradigm for the treatment of allergic diseases. J invest Allergol Clin Immunol. 2018:28(3):139-50.

9. Drazen JM, Harrington D. New biologics for asthma. N Engl J Med. 2018:379(26):2533-5.

10. Pavord ID. Oral Corticosteroids-dependent asthma: current knowledge and future needs. Curr Opin Pulm Med. 2019:25:51-8

- Manuscript received April 4, 2019; accepted for publication April 16, 2019.

\section{MJ Alvarez Puebla}

E-mail: mj.alvarezpuebla@cfnavarra.es 